Association for Information Systems

AIS Electronic Library (AISeL)

\title{
Making Indian Cities Smart: Framing Incongruencies and Reconciliation
}

Priya Seetharaman

Indian Institute of Management Calcutta, priyas@iimcal.ac.in

Jocelyn Cranefield

Victoria University of Wellington, jocelyn.cranefield@vuw.ac.nz

Surajit Chakravarty

Indian Institute of Management Calcutta, schakrav@iimcal.ac.in

Follow this and additional works at: https://aisel.aisnet.org/icis2019

Seetharaman, Priya; Cranefield, Jocelyn; and Chakravarty, Surajit, "Making Indian Cities Smart: Framing Incongruencies and Reconciliation" (2019). ICIS 2019 Proceedings. 4.

https://aisel.aisnet.org/icis2019/digital_government/digital_government/4

This material is brought to you by the International Conference on Information Systems (ICIS) at AIS Electronic Library (AISeL). It has been accepted for inclusion in ICIS 2019 Proceedings by an authorized administrator of AIS Electronic Library (AISeL). For more information, please contact elibrary@aisnet.org. 


\title{
Making Indian Cities Smart: Framing Incongruencies and Reconciliation
}

\author{
Completed Research Paper \\ Priya Seetharaman \\ Indian Institute of Management Calcutta \\ Diamond Harbour Road, Joka, \\ Kolkata - 700104 \\ priyas@iimcal.ac.in \\ Jocelyn Cranefield \\ Victoria School of Business \\ Victoria University \\ Wellington, New Zealand \\ jocelyn.cranefield@vuw.ac.nz
}

\author{
Surajit Chakravarty \\ Indian Institute of Management Calcutta \\ Diamond Harbour Road, Joka, \\ Kolkata - 700104 \\ schakrav@iimcal.ac.in
}

\begin{abstract}
Smart cities aim to utilize information technologies to improve efficiency and effectiveness of urban infrastructure and service delivery, and to advance the agenda of sustainability. Smart cities typically involve a variety of stakeholders with diverse agendas. In this study, we seek to explore incongruencies in stakeholder perspectives and identify how these are negotiated and reconciled. We examine the evolution of a smart city initiative in Bhubaneswar, an Indian city, over a three-year period, focusing on the divergence of stakeholder perspectives. We draw upon Technological Frames of Reference theory in identifying framing incongruencies present in the city's foundational frames. We understand these through the underlying frameworks of archetypal core constitutive values. We delineate mechanisms used to reconcile the incongruencies through building a shared foundational frame, boundary spanning, perspective seeking and cultural adaptation of technology-in-use. The study has implications for deliberately designed mechanisms that can aid inversion and negotiation of incongruent frames.
\end{abstract}

Keywords: Technological Frames of Reference, Urban, Traffic, Bhubaneswar, Stakeholders

\section{Introduction}

Many governments and city administrations around the world are increasing investments in smart city initiatives in the hope of transforming their congested urban regions. Investments in such initiatives across the world is nearing USD 100 billion (IDC 2019), yet, much remains to be done to make our cities liveable, sustainable and inclusive. Apart from developed economies such as the UK, Denmark, Canada, Japan and others, which are using the Smart City (SC) bandwagon to restructure their cities, many developing countries such as China, Rwanda, Brazil, and India (the setting for this study) are not far behind (Eden 2018).

The SC policy in India is one of very few instances globally where a central government has taken it upon itself to shepherd local governments through the process of becoming "smart", a model that relies on the integrative capabilities of the implementing agency (Praharaj et al. 2018) while allowing for a bottom-up approach to identifying context-sensitive solutions to urban needs. Moreover, significant economic, educational and digital divides prevail in countries like India (Khan et al. 2018) thus drawing critical eyes to a technology-driven urban regeneration initiative. It is precisely this very dichotomy that renders SC initiatives an interesting canvas to examine diversity of perspectives as both, an urban redesign and redevelopment exercise (Hoelscher 2016). 
Research in this fast-emerging interdisciplinary area highlights that smart cities attempt to fulfil multiple urban development objectives, solve a variety of problems typical to modern cities and achieve many different outcomes (Anthopoulos et al. 2019; Chourabi et al. 2012; Nam and Pardo 2011). Accordingly, the Smart City (SC) is seen as a multi-faceted concept. While some authors have attempted to forge together integrative frameworks (such as Chourabi et al., 2012) that include factors critical to SCs such as policy context, economy, governance, management and organization, technology, communities, infrastructure, and natural environment; others have also included data, knowledge, energy, smart city architecture and health as dimensions of a unified smart city model (Anthopolous et al., 2019). The smart cities literature has also found a base in the e-government area of research drawing upon three fundamental aspects institutions, technology and people, where in the context of smart cities these manifest in the strategic principles of governance for institutional improvement; integration of infrastructures and technologymediated services; and social learning for strengthening human infrastructure (Nam \& Pardo, 2011: p. 282). Citizens' interaction with the government, driving improvement across quality of life in an urban environment, enhancing mobility and streamlining traffic along with using ICTs and data to create insights to effect these have also been viewed as integral to a smart city (Giffinger and Gudrun 2010). With such a kaleidoscope of possible goals, which may be variously combined in response to a particular city's specific context, it is unsurprising that there is no common clear definition of what a smart city constitutes (Albino et al. 2015; Nam and Pardo 2011). The smart city phenomenon can therefore be seen as a complex, fluid concept that is widely employed to help cities solve "tangled and wicked problems" of urbanisation that span social, political and organisational realms (Nam \& Pardo, 2011: p. 185).

As a complex "sociotechnical system of systems" (Ojo et al. $2014:$ p. 2), smart cities typically involve a large ecosystem of stakeholders (Chourabi, et al., 2012). Large scale inter-organizational information systems such as SC projects often give rise to participation and adoption related challenges mainly due to the multiplicity of stakeholders with very different frames of reference and diverse agendas (Boonstra and de Vries 2008; Pouloudi and Whitley 1997). Developing a deeper understanding of people's sense-making of technology and its associated consequences in large-scale IT-enabled change (Davidson 2006) such as at the urban city-level, is therefore, both necessary and useful given the increasing IT-enabled interactions between cities and residents through demand-pull and technology-push approaches (Kummitha 2018). In this context, we view stakeholders as people, groups or institutions who are likely to affect or be affected by the phenomenon and broadly apply the principles suggested by Pouloudi and Whitley (1997) taking cognizance of context, time frames, inter-relationships, and political issues in identifying stakeholders. Identifying stakeholders, albeit complicated, is essential to help understand the interactions, negotiations and process of mutual adaptation that is required to further the project. Our study asks:

\section{What are the different stakeholder perspectives in the context of a smart cities project? and}

\section{How are the different stakeholder perspectives reconciled?}

To enable us to appreciate the nuances in the different perspectives, we draw upon the technological frames of reference (TFR) theory (Orlikowski and Gash 1994) and its extensions (such as Cornelissen and Werner 2014; Young et al. 2016). Through TFR, we seek to explore stakeholder perspectives and identify how these are negotiated and reconciled. To address these questions, we conduct an in-depth analysis of Bhubaneswar Smart City (BSC), the first of 100 smart cities to be implemented in India.

The remainder of the paper is structured as follows. We begin with an overview of the background drawing from literature on SC and the TFR theory. We then describe our methodological choice, the context and data sources. The findings are presented as foundational frames followed by reconciliation mechanisms identified. We conclude the paper, re-positioning our findings in the context of the literature on smart cities and TFR theory and discuss contributions and limitations of the current study.

\section{Background}

We briefly summarize the three streams of academic research that inform our current study - SC as ITbased urban initiatives, SC in India and the theoretical lens - technological frames of reference that we adapt in the current research. 


\section{Smart Cities as IT-based Urban initiatives}

A variety of interpretations have been assigned to "smart" such as digital and intelligent city that incorporates sustainability and livability (Chourabi et al. 2012), technology enabled (Harrison et al. 2010), forward-looking (Giffinger et al. 2007), resource efficient (Hoon et al. 2014) and assemblage of human and non-human actors (de Waal and Dignum 2017). Non-ICT based characterizations of "smart" in the context of SC have also been provided such as having infrastructure and services that serve local needs with intelligence (Anthopoulos 2017). The nature of urban administration is changing to one that collaborates with other departments and with communities in an attempt to "become more transparent and accountable, manage resources more effectively, and to give citizens access to information about decisions that affect their lives" (Nam and Pardo 2011). Gil-Garcia et al. (2015) combine practical tools with academic literature to create a comprehensive conceptualization of a smart city where the emphasis is on urban administrative elements, societal considerations and physical environment of the city while keeping the technology elements as the integrative layer. However, such elaborated conceptualizations of SC that include the people, community and governance aspects have occupied far lesser space in the dominant discourse. For this study, we employ a practice-oriented definition of a smart city as a "citizen-centric technology-enabled initiative to design and redevelop urban infrastructure, spaces and service delivery with the objective of making cities livable, sustainable and inclusive" (Bibri and Krogstie 2017).

The two paths, i.e. the ICT-driven, technology-push approach to the concept of SC (Harrison et al. 2010) and a people-oriented, human-driven method to it seem to co-exist in academic literature (Kummitha 2018; Perez-Martinez et al. 2013). The need to go beyond technology perspective can hardly be emphasized more given the increasing possibilities that technology itself offers for a more socially-grounded, citizen-centric perspective. Webster \& Leleux (2018) highlight that there is a disconnect in the discourse between the potential of ICTs to bring about transformation and the reality in public service environments especially since administrative and business-like solutions are easier to achieve than civic engagement, participative, co-production and co-creation of public services. The global discourse on SC thus leaves much to be desired in social, cultural and environmental aspects.

\section{Smart Cities in India}

In the Indian context, the academic literature on SC has thus far focused on identifying key issues and challenges while also calling for a deeper inquiry into the design, implementation and governance of the policy (Khan et al. 2018). The idea of SC in India took formal shape when Ministry of Housing and Urban Affairs (MoHUA) announced an all-India cities challenge to participate and win funding for re-design, redevelopment and re-densify urban spaces (GoI 2016). The Smart Cities (SC) Mission in India, launched in June 2015, provides policy directions and funding to municipal governments for executing urban infrastructure projects, particularly those that apply advanced planning techniques and information technology (IT) to urban management. One hundred cities in India were nominated by the different states for funding under the SC mission of which 20,13, 27, 30 and 9 cities were selected under five rounds of applications respectively (GoI 2016) over a twenty-four-month period between 2016 and 2018. Since then, cities have received funding, initiated projects, executed them and implemented associated information technology application environments. Details of the challenge are presented in Appendix 1.

As the policy and its implementation evolved, two schools of thought have dominated the SC academic discourse in the Indian context - a populistic, aspirational narrative, 'promotional bombast' (as Harris 2015 terms it) that projects the mission as aiming to transform the currently 'dysfunctional' state of urban management by adopting technological solutions (Kumar et al. 2018) and another which cautions the policy makers against the excessive corporatization which can turn them into walled cities 'dividing its elite citizens from the rest of the population' (Khosla 2018). Dysfunctionalities in Indian cities, on the one side, have been seen as resulting from the lack of sufficient industrialization and dependence on the informal sector (Ramachandran 2014) while on the other, are attributed to the "take-off and industrialize" meta growth models which mimic the linear model of western development (Khosla, 2018) or simply as manifestations of recurring breakdowns in urban administration (Burte 2014).

Thematically, the academic research on SC in India has analyzed barriers and challenges to implementing smart city initiatives; contextualized technological possibilities and embarked upon policy-level critical analyses such as those on the overall SC mission, issues of citizen participation and the hollowing of local 
governance. Rana et al. (2018)'s discussion of key barriers of SC from a review of existing literature and views of experts can be categorized under the first theme, where they find that governance, is a key concern in developing a SC network. As an example of studies of the second category, Kummitha and Crutzen (2019)'s qualitative enquiry revealed that normative institutions played a constraining role on citizen-led initiatives although regulatory institutions supported them. On the issue of citizen participation in smart city initiatives, academic literature has been fairly critical and emphasized the need to go beyond the obvious means of achieving participation. Consultation in the smart city mission of Dholera, a smart city project in the state of Gujarat, for instance, has been studied as state-mediated 'deliberative democratic' encounters (Datta 2015). Concerns arising from corporate envisioning of SC quite evident from the plethora of technological implementations by vendors seem to result in cities speaking the "language of corporate firms" (Datta 2015; Khan et al. 2018; Kummitha 2018).

\section{Technological Frames of Reference}

Framing theory considers how groups of people construct, articulate and share meanings concerning the nature of so-called 'reality'. A frame, or set of meanings, is transmitted (or activated) when it resonates, or gains salience, with the ways in which a particular group of people understand the world (Wiesman 2011). Orlikowski and Gash's (1994) technological frames of reference (TFR) theory has been a seminal theory of framing (Davidson and Pai 2004) in IS literature. As an accepted approach for examining the assumptions and knowledge about technology that people have, it has been used for understanding how individuals and groups differ in their understanding of technology and the implications of such divergences. TFR is "the core set of assumptions, expectations, and knowledge of technology collectively held by a group or community" (Orlikowski and Gash, 1994 p. 199). TFR not only concerns how people perceive technology, but also how they understand "the specific conditions, applications and consequences of that technology in particular contexts" (p.178). Orlikowski and Gash also identified three frame domains of TFR: the nature of technology (people's understandings of its capabilities and functionality), 2) technology strategy (people's views of why their organization implemented a technology), and 3) technology in use (people's understanding of how their organization will use a technology and the consequences of its use) (p. 183-184). Although these three technological frame domains are seen as being widely applicable, they have been supplemented by additional frame domains; such as the IT capabilities, business value of IT, and IT-enabled work practices (Davidson 2002); technology implementation and contextual insights (Young et al. 2016).

Different groups of stakeholders may share TFRs or contest them. In the latter case, this may lead to political contests between frame meanings (Young et al. 2016) and in the former, develop congruent frames which become the norm through a process of self-reinforcement (Mazmanian 2013). Young et al. (2016) argue that contestation of frames can be both within a group of stakeholders (inconsistencies) and across groups (incongruencies), the latter being more common in inter-organizational information systems where stakeholders are likely to be a broader range of people and organizations interested, affected or in a position to influence the information systems development and use (Pouloudi and Whitley 1997). Such incongruencies in frames are likely to manifest in patterns of divergent enactments (Davidson and Pai 2004), reflecting resistance and skepticism, resulting in poor appropriation of information technology. Stabilization and consensual closure of incongruent frames are often difficult to achieve, especially when diverse stakeholder groups are involved (Mcloughlin et al. 2000) since they are more likely to bracket cues based on their varied professional and organizational identities (Elbanna and Linderoth 2015). However, 'institutional entrepreneurs' or 'configurational intrepreneurs' act as change interventionists in challenging existing belief systems (Elbanna and Linderoth 2015; Mcloughlin et al. 2000) and aid reconciliation of incongruent frames through a process of organizing vision (Davidson and Pai 2004); boundary spanning (Cranefield and Pries-heje 2019) and perspective making (Boland and Tenkasi 1995). In the context of the smart city, there is little evidence of application of this theory except Madsen (2018), who uses TFR theory to identify two distinct technological frames concerning the nature of data within a single organizational unit in Smart City Copenhagen. The current study highlights the importance of understanding a wider range of smart city stakeholder perspectives and addressing incongruencies in practice.

\section{Methodology}

Our choice of research methodology is shaped by the rationale underlying our research questions. One, stakeholders of a particular technology-led initiative are specific to a context and their perceptions are often 
intensely embedded in the context in which they function. Second, in a smart city initiative, often a collection of integrated, threaded urban development-focused technology-enabled projects that are designed for a unique space, the boundaries between the technology-enabled phenomenon and the sociocultural context are explicit. Third, an examination of the perspectives of diverse stakeholders and the mechanisms used to reconcile the incongruences if any, should be able to capture the narrative richness in their interactions. This research study therefore demanded in-depth investigation of a contemporary phenomenon within its rich real-life context. This need is best fulfilled by an interpretative approach (Myers 2017) which aims to develop an understanding of the context and the process by which the ITenabled initiative intensely affects and is in turn influenced by the context (Walsham 1995).

We chose to study Bhubaneswar (Bbsr), the capital of Odisha state, in south-east India, as a single case study of India's SC mission implementation. A profile of the city is presented in Appendix 2. Bhubaneswar's administrative structure is representative of most medium sized cities in India, while its urban evolution and socio-economic milieu sets it apart. The city received a high ranking in the original SC challenge in 2015 and later won accolades from American Planning Association under the Pierre L'Enfant International Planning Award. The Bhubaneswar Smart City (BSC) team used a combination of citizen consultation voting process and the city administration's assessment to decide both the locale for Area-Based Development (ABD) and priority of pan-city solutions. In pan-city solutions, urban mobility had the highest number of votes from the citizens (GoI 2015). Our analysis of secondary data on the progress of urban development and technology-enabled pan-city solutions projects in various SCs seemed to indicate that the BSC team had indeed made considerable progress since having received the SC mission funding despite numerous constraints. This evolution of the BSC project since 2016 (Figure 1) piqued our academic interest.

\section{Figure 1: Timeline of Significant Events in Bhubaneswar Smart City}

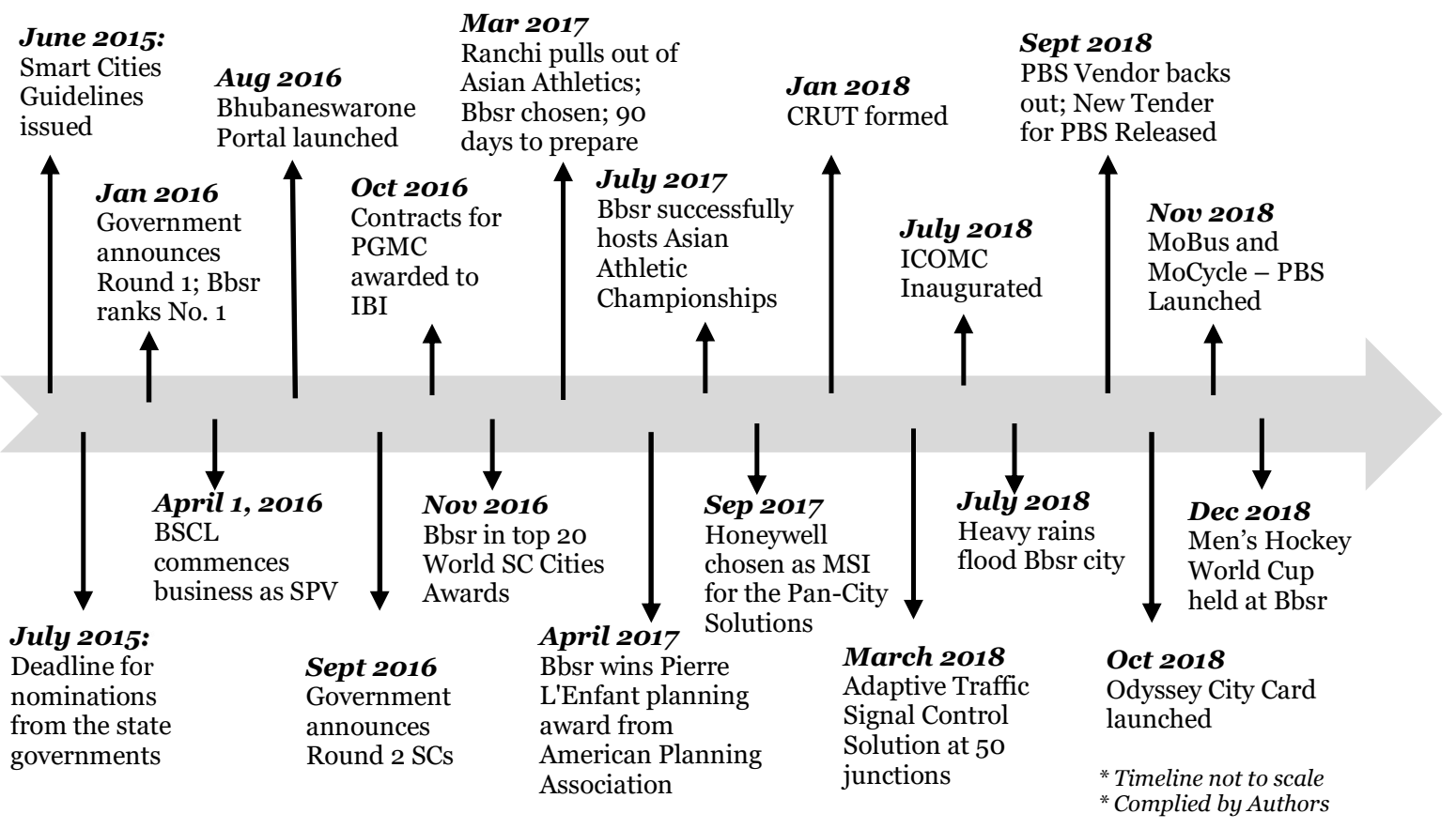

Within the BSC projects, we chose transit, traffic and urban mobility as the focus in the context of the larger BSC initiative. There is a need for growing cities to be aware of the importance of the "road" as more than just a connecting link between one point to another. By investing in improving transit, traffic and urban mobility, cities can aim to achieve sustainable economic growth while reducing economic burden for private individuals and public agencies (EIU 2017) and at the same time prevent marginalization of economically weaker groups in cities (Qamhaieh and Chakravarty 2017). 
Bhubaneswar is perceived as a rapidly growing city in terms of increasing population and growing vehicular density. BSC team also identified road lane blockages, heterogeneous vehicle composition and lack of awareness of traffic rules, poor driving habits as being major challenges in urban mobility (GoI 2015). As a response to this issue, they chose transit-oriented development and urban mobility as one of the components of ABD and intelligent traffic management, smart parking and transit operations as part of the Pan-City Solutions. Our current study therefore focuses on these initiatives (Figure 2).

\section{Figure 2: Stakeholders and Projects of Bhuaneswar Smart City}

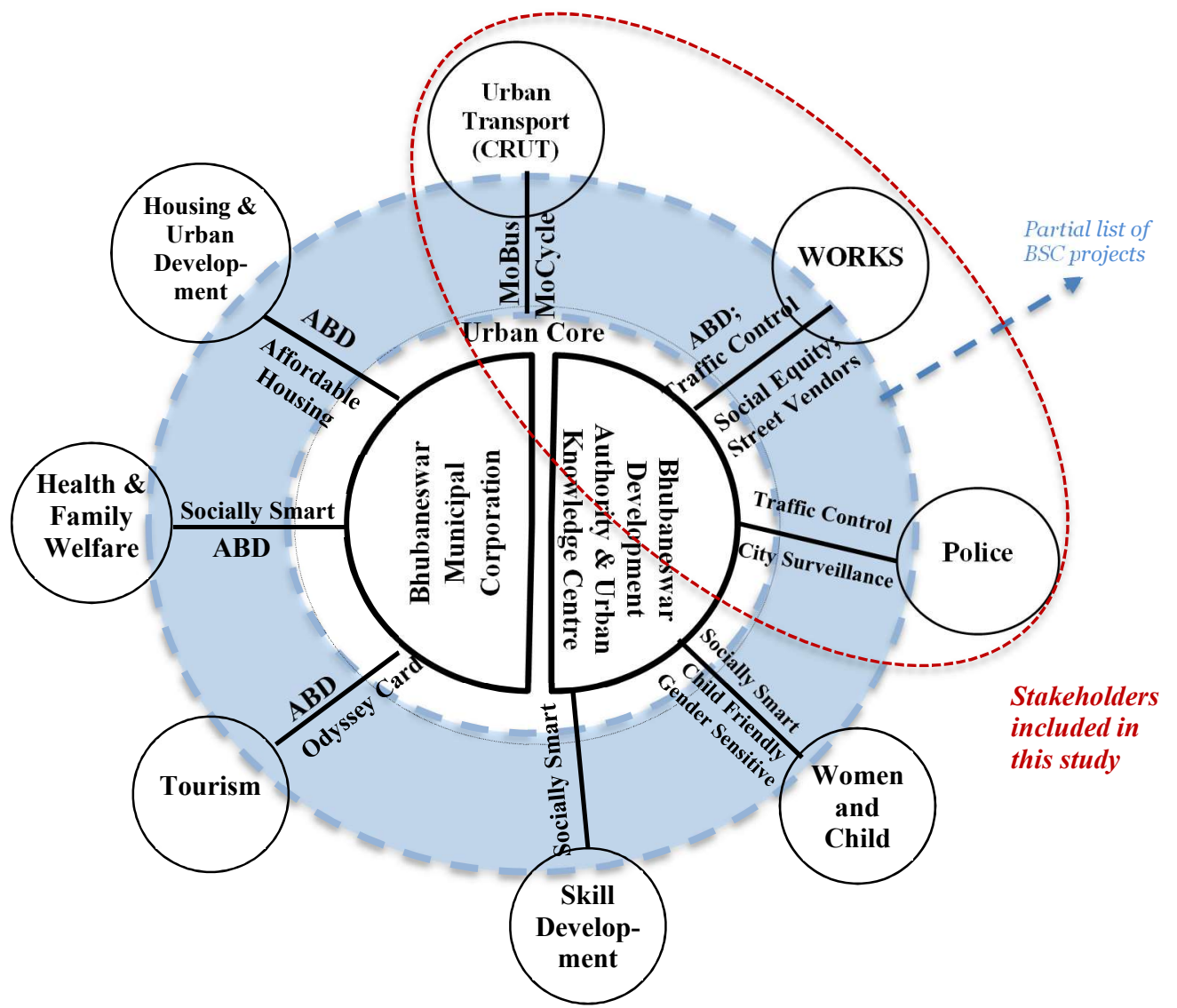

\section{Data Sources}

Sources of data (Table 1) for this study included both primary (dominantly face-to-face and telephonic interviews) and secondary (dominantly published data sources). Our choice of respondents drew from Pouloudi and Whitley's (1997) principles for identifying stakeholders. We use the term stakeholder to refer to people, groups or institutions who are interested in the BSC's projects, likely to affect it or are likely to be affected by it. Agencies were thus identified as stakeholders based on the role they played in the planning and implementation of various projects and their interrelationships with BSC team, the nodal agency (Chibber 2002). Figure 2 represents the stakeholders and the BSC projects they are associated with. Partner agencies are private vendors contracted based on open tendering processes to execute the different projects.

As urban mobility projects were still in nascent or pilot stages and citizens were yet to become regular involved users of the BSC's digital services, we focused on the provider perspective. We engaged in a process of reconnaissance through multiple visits to the SC mission in the central government and the BSC team. We extended our list of interviewees through snowballing. A total of 17 respondents were interviewed over a 7-month period. We use generic roles to identify our interviewees in order to ensure anonymity. SC projects are typically multi-level government projects such as in India where the central government is involved through the overarching SC mission, the state government forms the SPV and is involved in 
allocation and control of resources while the execution is the responsibility of municipal city administration. Such a tiered initiative brings forth significant complexity in design and implementation demanding focused attention to the service providers' perspective.

Table 1: Sources of Primary and Secondary Data

\begin{tabular}{|c|l|}
\hline \multicolumn{2}{|c|}{ Primary Data (Interviews) } \\
\hline $\begin{array}{c}\text { Code } \\
\text { Used }\end{array}$ & $\begin{array}{c}\text { Role - Associated Agency } \\
\text { (Duration in Minutes) }\end{array}$ \\
\hline CM1 & Key Person - Central Mission (75) \\
\hline CM 2 to 4 & Consultants - Central Mission (180) \\
\hline NA 1 to 2 & Tech Leads - Nodal Agency (110) \\
\hline NA3 & Project Lead - Nodal Agency (40) \\
\hline NA4 & Key Person - Nodal Agency (50) \\
\hline NA5 & Domain Expert - Nodal Agency (30) \\
\hline PA 1 to 3 & Consultants - Partner Agency (235) \\
\hline PA4 & Key Person - Partner Agency (75) \\
\hline ST 1 to 4 & Domain Experts - Stakeholder (200) \\
\hline
\end{tabular}

\begin{tabular}{|c|l|}
\hline \multicolumn{2}{|c|}{ Secondary Data } \\
\hline $\begin{array}{c}\text { Code } \\
\text { used }\end{array}$ & \multicolumn{1}{|c|}{$\begin{array}{c}\text { Description of the Source } \\
\text { (Approximate Length in Pages) }\end{array}$} \\
\hline SD1 & BSC Proposal and Annexure (200) \\
\hline SD2 & Extracts from other city proposals (2000) \\
\hline SD3 & News reports on SCs in India (1114) \\
\hline SD4 & News reports on Bhubaneswar (72) \\
\hline SD5 & BSC Documents in public domain (1881) \\
\hline SD6 & Government Notifications (200) \\
\hline SD7 & Answers to Parliament questions (1000) \\
\hline SD8 & Transcripts of YouTube interviews (9) \\
\hline SD9 & BSC social media pages (NA) \\
\hline
\end{tabular}

\section{Analysis}

With mental maps of our research questions, the background literature and documented sources of incongruences in IT-enabled change especially in large scale initiatives, we analyzed around 7000 pages of textual data. We combined Orlikowski and Gash's (1994) and Young et al.'s (2016) frame domains to code the text and analyze patterns in the data. To this we added technology governance (people's understanding about who makes the technology decisions, what are the processes followed) and inter-stakeholder interaction (people's understanding about coordination and communication between different external and internal agencies involved in the technology implementation) given the uniqueness of the smart city initiative as a technology project. The longitudinal nature and diversity of technological projects required us to use four broad layers of information technology architecture including - infrastructure, applications, data, and analytics/decisions support, along with two general categories - overall smart city mission; knowledge and capacity building adding to six cross-codes. Our initial list thus contained 42 broad codes.

We used text analysis software NVivo(C) to organize our large dataset and to facilitate the text coding process. However, we did not use NVivo's automated coding options but coded the text manually. We also added new codes wherever data warranted them. Our approach is analogous to a combination of inductive and deductive approach to data analysis not uncommon in information systems research. One author coded the text along with the help of a qualified research assistant familiar with the context and trained in text coding using NVivo. Random quotes were chosen to be discussed amongst the authors to check the validity of the coding process. Disagreements were addressed through discussion and reinterpretation. Wherever possible, unambiguous definitions of codes were developed consensually. Once the data was coded, our subsequent analysis was composed of two stages. First, thematic conceptual matrices were created to help organize the data through a process of clustering and factoring (Miles and Huberman 1994). This helped identify the congruent frames and incongruencies. Second, we developed potential explanations for the reconciliation of inconsistencies observed in the data. In doing so, we had to iterate through the coded text, reanalyze the data and abstract the shift in frames through the associated manifestations while attempting to tease out explanatory mechanisms for such reconciliations. For instance, we asked of the data: how have collective popular perceptions of particular groups affected individuals of another group? How have the actions of a particular stakeholder been interpreted by another? What do stakeholders seem to make of the underlying power dynamics? Through such interrogations, we compared the reported progress of the projects and the reframing of perceptions. 


\section{Findings}

Our analysis of data revealed Bhubaneswar Smart City to be an emergent, multi-faceted phenomenon, conceptualized with a conglomerate of frames. These frames related to the smart city's purpose, the problems that it would solve, the value it would create, the solutions that would be provided for the city through technology and data, and how these solutions would be delivered in practice. This pluralistic framing can be seen as being associated with a set of diverse, potentially competing fundamental core value frameworks - 'worlds' or 'cities' (Boltanski and Thévenot 2006) and arose from the need to accommodate the diverse set of government objectives reflecting smart city frames that coexist in the global smart city rhetoric. Diverse ways of framing the smart city are documented in the literature and are seen as not being mutually exclusive in practice (e.g. Kitchin 2014).

The process of implementing BSC therefore needed to accommodate frame multiplicity and tension while delivering project outputs. This process involved ensuring legitimacy of the contributing values while promoting reconciliation when frame dissonance or frame contests occurred. In the sections below, we summarize the multiplicity of frames involved and their underlying values and then explore four mechanisms through which the smart city project managed frame multiplicity through promoted frame reconciliation and accommodation during the early stages of implementation.

\section{Multiplicity of Foundational Frames}

The novelty and newness of smart city as an initiative have evoked a variety of responses from the stakeholders. We observe these as foundational issue frames.

The SC mission in India, in its guidelines, states that "there is no universally accepted definition of a smart city" (GoI 2016) recognizing that each city should be free to define what they want their city to be. Respondents appreciated the flexibility given by the smart city mission in allowing them to do so

"What central smart city mission gave was a framework ..this is how you can improve your city for that we can help you with funding and by giving some guidance with expert opinions. Apart from that everything was on the city to make it happen. It's the city's ownership to take it forward" - PA1

However, in defining what smart city meant to them, many leaders articulated the overall purpose and strategy of the mission differently, revealing divergence in technology strategy (Orlikowski and Gash 1994). One leader emphasized citizen participation and ownership in order to successfully make a city smart, encapsulating the 'civic' aspect of a city:

.. should focus on smart governance, improved living conditions and more livelihood opportunities to match the growing urban population...Active participation of citizens is indispensable. If citizens are callous and do not take ownership in governance, no city can be smart. - SD8

another focused on efficiency in urban administration and governance:

A smart city is built with the objective of doing more with less, using technology...our objective is to have more efficient systems in governance, in the delivery of public services, in the management of city infrastructure and management of citizens' day to day life. - SD8

The role of technology in the SC mission has also been perceived in myriad ways, some broad and others far more precise in their expectations from the technology-enablement of the city infrastructure and services suggesting multiplicity in perceived nature of SC technology (Orlikowski and Gash, 1994) and in frames relating to technology implementation (Young et al., 2016). For example, some stakeholders' expectations of efficiencies in urban governance highlight the constitutive value of the industrial city (Table 2) such as those expressed in popular press (SD8):

We would like to infuse a lot of technology in governance not for the sake of technology but for the sake of transparency, efficiency, bringing down the time for giving services to the people.

Interestingly, transit and transport occupied a dominant place in the discussion on what it meant to make Bhubaneswar smart. Some stakeholders were also keen to use the SC initiative as a means to make transport and other services in the city more environment-friendly and sustainable (Table 2). A senior project leader remarked 
Smart cities are not just about technologies, it is about a smarter way of life, a more sustainable way of life... Ease of life. The city is a maze out there. Why should I be so hassled to just go from one place to another place, why I should be scared of travelling in my own city. Technology should enable me to enjoy travelling in my city. - NA4

Table 2: Constitutive value framework with illustrative frames

\begin{tabular}{|c|c|c|}
\hline $\begin{array}{l}\text { Constitutive } \\
\text { value ("City")* }\end{array}$ & Valued Characteristic & Manifestation in Bhubaneswar Smart City \\
\hline Inspirational City & $\begin{array}{l}\text { Spontaneous vision, } \\
\text { imagination, creativity }\end{array}$ & $\begin{array}{l}\text { If we are able to envision together, we will be able } \\
\text { to implement together }\end{array}$ \\
\hline $\begin{array}{l}\text { Domestic City } \\
\text { (City of Tradition) }\end{array}$ & $\begin{array}{l}\text { Loyalty and respect of } \\
\text { authority based on assigned } \\
\text { roles, status and duties }\end{array}$ & $\begin{array}{l}\text { To improve enforcement and influence citizen } \\
\text { behaviour, ICOMC proposes to combine issuing } \\
\text { fines with innovative modes of issuing oral } \\
\text { commands for remedial actions through } \\
\text { loudspeakers at such hotspots from central traffic } \\
\text { operations room }\end{array}$ \\
\hline $\begin{array}{l}\text { Opinion } \\
\text { City of Reputation }\end{array}$ & $\begin{array}{l}\text { Achievement of recognition } \\
\text { and prestige. }\end{array}$ & $\begin{array}{l}\text { We told [citizens] what this whole competition is } \\
\text { all about, that this is our chance to defeat the } \\
\text { other cities... Within a period of } 6 \text { months, (this) } \\
\text { was the place to be, it won the smart city }\end{array}$ \\
\hline Civic City & $\begin{array}{l}\text { Civic duty, suppression of } \\
\text { own interests in pursuit of } \\
\text { common good. }\end{array}$ & $\begin{array}{l}\text { We strongly believe that even the last man in the } \\
\text { city needs to be taken care of. It's not just about } \\
\text { building some jazzy infrastructure }\end{array}$ \\
\hline Merchant city & $\begin{array}{l}\text { Interests of competing actors } \\
\text { who take part in a } \\
\text { commercial game }\end{array}$ & $\begin{array}{l}\text { It adds huge value, it has increased commercial } \\
\text { property prices for sure, we get more revenue as } \\
\text { well as part of that. }\end{array}$ \\
\hline Industrial city & $\begin{array}{l}\text { Efficiency and } \\
\text { standardization. Science and } \\
\text { technology (and data) are } \\
\text { seen as powerful tools in the } \\
\text { service of industrial } \\
\text { development. }\end{array}$ & $\begin{array}{l}\text { Data is the new king. Until and unless we have } \\
\text { data available for each and every department } \\
\text { which gets collected, collated and analyzed at a } \\
\text { large scale, we will not be able to make optimum } \\
\text { decisions about allocation of resources and } \\
\text { increasing the efficiency of existing services } \\
\text { A smart city is built with the objective of doing } \\
\text { more with less, using technology. }\end{array}$ \\
\hline $\begin{array}{l}\text { Sustainable City } \\
\text { [added] }\end{array}$ & $\begin{array}{l}\text { Living in harmony with } \\
\text { environment and valuing } \\
\text { future generations }\end{array}$ & $\begin{array}{l}\text { It is about a smarter way of life, a more } \\
\text { sustainable way of life }\end{array}$ \\
\hline
\end{tabular}

The BSC initiative, from the perspective of stakeholders overseeing projects related to traffic, transit and urban transport, was aimed at ushering in order and efficiency. The issue frames included social inequity, poor infrastructure, lack of order on the roads, inefficient decision-making, poor agency coordination, and lack of people-centricity. The solutions mapped onto these issues were accordingly focused on improving system and decision-making efficiency through aggregation and analysis of data, using data to drive better policy, improving order (flow of traffic; compliance with traffic laws), and providing a more efficient and unified public transport network. The identified frames spanned all three "dominant understandings" of smart cities presented by Kitchin (2014), i.e. (1) SC as being principally about the changing nature of urban 
governance through instrumentation and data driven systems (2) SC as primarily concerned with improving urban policy to reconfigure human capital, creativity, sustainability, etc.; and (3) SC as using ICT to promote citizen centric development that fosters social, civic engagement, and accountable governance.

In order to better understand the reason for this frame multiplicity we sought to identify the underlying values of frames, using a framework of archetypal core values. Based on an analysis of political philosophy, Boltanski and Thévenot (2006) identify six constitutive value frameworks that structure social arrangements: inspirational, domestic, opinion, civic, merchant and industrial. These value frameworks (also referred to as 'cities') define distinct principles namely - spontaneity or artistic ingenuity; paternalism and hierarchy; opinion of others; collective well-being; competition; instrumental rationality and performance respectively (Denis et al., 2007: p.190-191). The frames relating to BSC smart city's nature and purpose were found to spanning all six fundamental, potentially competing archetypal core value frameworks. We identified a further core value relating to sustainability. Column 3 in Table 2 illustrates the mapping of BSC frames to these value frameworks or "cities".

\section{Frame Reconciliation and Accommodation Mechanisms}

BSC Limited (BSCL), as the nodal agency, along with its different partners has evolved mechanisms to reconcile the frame contestations and accommodate frame multiplicity. Such accommodations have been aimed at overcoming the divergence in understanding the perspectives and expectations, with the explicit objective of moving forward the various projects under the BSC mission. While the impact and efficacy of these mechanisms can only be validated through time, their manifestations can be observed in the everyday enactments (Elbanna and Linderoth 2015).

\section{Building a Shared Foundational Frame}

The vision for a smart Bhubaneswar as a livable, sustainable and inclusive city to which its citizens can connect to, that is efficient in governance and delivery of public services was a means of creating a foundational frame of reference. The average resident of the city has thus far seen Bhubaneswar as a city with a "chalta hain" (Hindi - roughly translates to 'anything goes') attitude (Sahu 2018). But when the state recommended the city to the SC Mission; the city authorities were seen taking keen interest in soliciting public opinion for preferred projects; and subsequently when the city won the SC challenge, there seems to have been a strong external motivator to see things differently.

Bhubaneshwar residents took (the challenge) to heart, they have been wanting an identity ...when we told them what this whole competition is all about, that this is our chance to defeat the other cities, it became like an IPL (Indian Premier League) pretty much. Bhubaneswar doesn't have a cricket team anyway, so this was the opportunity to show them that we are going to do it. - PA4

There were consistent efforts to build a shared vision and to reaffirm the vision through every interaction between the city and its residents. The city simplified the grand vision of a technology-enabled inclusive, livable and sustainable city to simply 'My city' reflecting the opinion city of reputation (Table 2). In the early stages of the SC proposal preparation, the city initiated a contest for vision statements and titled it "My City, My Dream" (SD4, October, 11, 2015). One leader articulated it as:

First is vision- whether the city and the citizens are ready to be connected with the municipal council and government; whether they are able to think through what they want in the future, that's the beginning point. If we are able to envision together, we will be able to implement together. - SD8

A simplified, inclusive vision as a foundational frame allows stakeholders to lighten the burden of interpretation, thus facilitating the change process (Davidson 2006). Creating legitimacy for such simplified vision involves challenging existing shared belief systems (Mcloughlin et al. 2000). For the urban administration team which had lost its connect to the real urban issues and solutions, this presented an opportunity to revert to the basics of the city as being transit-oriented. A consultant remarked:

People who have been working as urban technologists for 30 years...we are telling them something that they used to know... and we tell them that it is better to do it this 'new' way...somewhere they also realize that they were taught all this in 'urban school' but given everyday practical realities, they have forgotten all this along the way - PA3 
The role of technology in aiding such simplification of vision to one which brings the city "together" administratively was also articulated:

When we told them that the ICOMC (Intelligent City Operations and Management Centre) is the only way we can have an integrated way of looking at the city, we are not as a society used to communicating.....it does not matter whether I am a bureaucrat or an urban engineer. I don't talk to my peers in other departments. The only way of making them do it is to bring them together under one roof and demonstrate the utility of an integrated city perspective. - PA3

\section{Boundary Spanning}

The issue of boundaries between departments engaged in operationalizing the vision of Bhubaneswar as a smart city were often blurred resulting in questions being raised about the nodal role that BSCL played. In its smart city proposal, the city states as one of its weaknesses

a large number of agencies are working in Bhubaneswar resulting in jurisdictional ambiguities. Presently, five departments are developing and maintaining road infrastructure (GoI 2015)

Such jurisdictional ambiguities are likely to give rise to friction and tensions between different entities exposing the need to consciously build cross-boundary relationships. In order to forge symbiotic relationships with its stakeholders and overcome contestations of institutional logics not uncommon in government bureaucracies (Busch et al. 2018), BSC evolved an overarching institutional framework with two structural mechanisms. First, a cross-leadership mechanism that allows BSCL staff to operate seamlessly with other urban departments, by having the BSCL Managing Director (MD) as part of leadership teams of stakeholder agencies; and along with it a means of maximizing coordination by interlocking directorship with other state agencies (Tsui-Auch 2004) where heads of stakeholder agencies are members of BSCL leadership team. One respondent stated:

..what (one person) has been able to do over the last 4-5 years, has changed the mindset of people from top to bottom. People above him also, they have started talking the same language. - PA3

Most respondents emphatically mentioned the MD's cross-boundary leadership as being the reason for ease of execution of many projects, facilitating inter-departmental coordination and enabling a mindset change through a process of reframing. The work of boundary spanners who cross structural and cognitive boundaries, translating between interpretative worlds is known to play a key role in shaping meanings to align with change (Cranefield and Pries-heje 2019).

...and then this whole shift happened, you had one person who was the vice chairman of the Urban Development Authority, who was also commissioner of the municipal corporation, also heading the transport authority, the SPV ... A lot of hats to wear. But, I see it as a plus...There are connections between different things. - PA4

Designing the BSCL as a nodal agency and empowering it to make decisions that relate to multiple urban development aspects through the interlocking leadership team

.. has made deployment and execution easy and very high because everything routed from the upper end so we don't go to the different departments and talk, so we lay out a proposal, we send it across, we ask the relevant people who can do it and then it is accordingly driven by those people who really want it to be done. - NA2

A second institutional framework mechanism included the formation of a Bhubaneswar Urban Knowledge Centre (BUKC) as a knowledge, capability and resource center for all aspects related to planning and coordination between the city agencies.

..came up with BUKC, it is a sort of a technical one stop resource center for all city agencies... whatever questions and concepts that they want to get clear, BUKC is the one explaining it, because...the capacity is just still not there (in existing departments) - PA4

The boundary spanning role of BUKC is also evident in its structural positioning. BUKC is a unit of the urban development authority thus foregrounding its role as the primary planner and designer for all aspects relating to the smart city initiative: 
See...BUKC is a part of the development authority, and development authority is long term. BSCL is for 5 years. But we plan to continue BUKC, as we just want to keep evolving as a city. The development authority is where BUKC is going to be and it serves BSCL, and all the agencies as well.... So BUKC should be in urban core. - PA4

\section{Perspective Taking and Perspective Making}

In ensuring the progress of an inter-organizational technology initiative, an assessment of the embedded power dynamics aimed at understanding each stakeholder's strategic position and the potential impact positive and negative of the system to be implemented, may aid in design of interventions that can overcome potential barriers (Boonstra and de Vries 2008). Stakeholders influence each other in the process of negotiating IT-enabled change and reinterpret their stances through the evolution of the project (Mcloughlin et al. 2000). This involves a process of mutual perspective taking symbolizing exchange of knowledge and integration of perspectives from across organizations, coupled with perspective making, a process of strengthening internal knowledge within the group or organization through construction of narratives (Boland and Tenkasi 1995). Such knowledge sharing mechanisms may also aid the process of bracketing internal sociomaterial constitution with equivalent contextual sociomaterial conditions lying outside the institutional boundary (Avgerou, forthcoming). BSC team traversed many extra yards to seek opinions and expectations of the city's residents and other stakeholders in the run up to the challenge:

(one of the key leaders) had made extra efforts to make the process of SC proposal preparation more inclusive...involving citizens, urban leaders, participating government agencies, even NGOs working in urban related issues...so that has made people feel they are doing it for the city - PA3

Subsequently, during the operationalization and implementation of the different projects, the dominant role, and justifiably so, was played by the development authority and municipal corporation, i.e. the urban core (Figure 2). Yet, in an attempt to sustain the momentum of intensive planning and deliberate coordination, BUKC was created, as an "extension of the development authority" (SD4, August 11, 2018):

Here we saw BUKC as an actual knowledge center that we are trying to create versus a typical program management consultancy. The intent makes a difference...the intent from the beginning was that we have to build the capacities of everyone as well, it is not just delivering regular reports. - PA4

Design - both urban as well as technology, was also being used as a means of making perspectives and strengthening knowledge within the urban core. BUKC's role as a policy, planning and research agency along with identifying ways to leverage tools and technologies to make the city administration efficient and effective aided this process of re-design.

Our teams were at it for 4,5,6 months. Everyday. We cannot achieve behavioral change without that kind of persistence. It is not just that I build the infrastructure and leave it. But I have to make you aware of it. And I have to make sure that the new practice continues. - PA3

The process of making perspectives involved aiding stakeholders in bracketing cues afresh. Institutional entrepreneurs catalyze stakeholders' breaking away from existing mental models helping them absorb new perspectives and new ways of working with technology (Elbanna and Linderoth 2015).

\section{Cultural Adaptation of SC Technology in Use}

During the BSC implementation, frame contests emerged in relationship to the use of technology for traffic monitoring at the command and control center to introduce a new, "industrial city" paradigm of order in city traffic and transit. These contests (occurring in the Technology-in-Use frame domain) were addressed by adapting technology and its use to better suit cultural norms and values. Prior to the smart city, there was "complete disregard for traffic signals, parking norms and pedestrians" (SD1). This can be explained by the deeply embedded cultural value of "chalta hain" (roughly translates from Hindi as anything goes) which framed traditional norms for both driving and policing. Traffic violations were rarely enforced and any on-road order was achieved by ad-hoc manual signaling by police. Bhubaneswar's smart city proposal undertook to transform both citizen and policing traffic norms through electronic ticketing (e-challans) and the use of sensors to introduce green lights flows. The traditional frame of chalta hain can be seen as directly challenged by the "industrial city" framing of order-as-efficiency through technology. There was strong 
initial resistance to the extensive use of traffic lights from some of the stakeholders as it was perceived to be unnecessary for such a small city and due to loss of flexibility.

Middle ground was soon identified and the resistance was overcome by perpetuating the hands-on approach to maintaining order in the use of technology. A system of loud hailers was installed at intersections, allowing police to call out to drivers of offending vehicles from the control room. This can be seen as appealing to the "City of Tradition" (or Domestic City, Table 2) value (Boltanski and Thévenot, 2006). This again demanded negotiation and reconciliation with the traffic department. BSCL reasoned that the command and control center from where live feeds of traffic were available would provide greater comfort for the traffic police than standing in the heat on roads but at the same time allow them to systematically control traffic flow and driver behavior.

The algorithm that used sensor data to determine green light flows was originally created for an organized traffic environment common in developed countries. It was based on an assumption that cars in turning lanes wanted to turn. Such stringent traffic norms were not common in Bhubaneswar and therefore demanded behavioral change amongst drivers, a painstaking long-term process. BSCL therefore adapted the algorithm to reflect the reality of driver behavior and speed up benefit realization. Such adaptation was based on negotiations and reconciliation with stakeholders in the Police department.

\section{Discussion}

Frame reconciliation is a complex iterative process (Azad and Faraj 2008). In our analysis of Bhubaneswar Smart City visioning and implementation, we illustrate through the context of frame multiplicities how frames are socially constructed and negotiated through an interactive process. The complexities in issue and solution framing can be seen as arising from everyday happenings and events, through the evolution of the BSC initiative, such as the orientation of the smart city mission as a competition and the divergent stakeholder perspectives that arise from the different foci and objectives of agencies involved. The frames were found to be underpinned by diverse, co-existing values. While these frames can be seen as incongruous and inconsistent (Young et al, 2016), we found that they are inherent in the foundational framing of the smart city mission, which allows for a variety of stakeholder perspectives: to promote cities that provide core infrastructure and give a decent quality of life to its citizens, a clean and sustainable environment and application of 'Smart' Solutions, etc. In negotiating these frames, dominant stakeholders resorted to different mechanisms which aided in building bridges while recognizing the fundamental constitutive values of different stakeholders (Denis et al. 2007). As can be seen, the frame domains and the mechanisms used for accommodating incongruent frames encompassed technology strategy, nature of technology and technology in use (Orlikowski and Gash, 1994).

Studies based on TFR theory typically view frames as needing to shift, be reconciled or aligned (Davidson, 2006; Young et al., 2016) in order for more effective IT-enabled transformation. Our study suggests that in a complex socio-technological environment such as a smart city initiative where intense frame multiplicity exists, such alignment or reconciliation is not only a time-consuming resource-intensive negotiation, but also a deeply political process. It shifts the focus of the nodal agency to understanding the refereeing of frames in such a co-opetition environment by identifying the underlying constitutive values associated with the different stakeholder perspectives. Such political re-framing practices can help make new frames resonate at a collective level so as to mobilise action in the desired direction (Kaplan, 2008: p.736).

Strategy making in such pluralistic contexts have been found to require a compromise between the different frames or logics that emerge, one that is legitimate should the ordering of the frames or logics be acceptable to the various stakeholders involved (Denis et al. 2007). Alongside such ordering, pluralistic contexts also bring forth conventions in artifacts, structures and processes such as, in the BSC case, boundary spanning structural forms (BUKC) and contextual innovations in technology use. The adaptation of certain smart city technologies and the manner of their use to accommodate cultural norms can also be seen as an adept frame bridging practice that facilitated a "truce frame" while gradually promoting a new 'industrial city' frame that values the creation of order through technology. The "truce frame" signifies that while consensus on the frames of reference have not been achieved, conflict and resistance due to incongruencies have ceased (Azad and Faraj 2008). 


\section{Conclusion}

In a newspaper opinion piece, senior journalist Srimoy Kar wrote

...the real test lies in its ability to transform itself into an able and efficient implementer, ensuring fastpaced, time-bound and holistic execution of plans. The biggest challenge, however, would be posed by the citizenry .. characterized by a sheer lack of civic sense and scant respect for law. Making the "unsmart people" smart should be an equal task as development of smart infrastructure. (Kar 2016)

In comprehending the divergent perspectives of different stakeholders of a smart city project in the city of Bhubaneswar in this study we draw upon the theoretical lens of "technological frames of reference". We discuss foundational frames of reference using constitutive value of smart cities. These arise from the stakeholders' perspectives of smart city's overall strategy, the nature of smart city technologies and the technology in use to operationalize smart city. The incongruencies in the frames so projected by different stakeholders are, over time, being negotiated. We present four reconciliation mechanisms - building a shared foundational frame, boundary spanning, perspective seeking processes and cultural adaptation of SC technology-in-use, which further explored the reconciliation process. Our analysis reveals that the negotiation and accommodation process was more complex than the alignment of frames that is seen as necessary in the implementation of intra-organisational information systems (Davidson, 2006). We explored a large group of inter-organisational stakeholders in a public IT-based urban initiative with potential for numerous incongruencies and inconsistencies; and focused on how multiplicity of frames is accommodated and reconciled through structure, process and adaptation of technology artifacts as truce frames.

Our study contributes to academic literature in two ways. One, it draws the attention of information systems researchers to the potential insights that the use of theoretical lenses such as sense-making, framing (Orlikowski and Gash 1994; Young et al. 2016) and reconciliation of frames can provide in a large-scale ITenabled change context (Davidson 2006) specifically one that is riddled with socio-technical complexities. Second, a contemporary socio-technical context such as that of a city-wide urban redevelopment initiative - a smart city project, where diverse individual and institutional stakeholders with their respective agendas come to play (Pouloudi and Whitley 1997) presents a unique setting observe how frames develop, interact and reconciliation mechanisms are negotiated along with the ensuing enactments. Doing so may help practitioners deliberately design mechanisms that can aid inversion and reconciliation of incongruent counter-productive frames while reinforcing heterogeneous but congruent frames (Mazmanian 2013).

We acknowledge three limitations of this study - generalizability, representativeness of the sample and inadequate involvement of citizens as stakeholders. The decision to choose a single case study arose from the need to focus on the contextual interactions between stakeholders. The limitations in generalizability from such single case-study research can, albeit to some extent, be overcome through the use comparative contextual case studies. We hope to do so in our future research work, where we expect to compare other Indian cities in similar stages of smart cities implementation. Limitations in data, such as representativeness of stakeholders, recall bias of respondents, not uncommon in short-term framing case studies (Davidson and Pai 2004) were, wherever possible, minimized through data triangulation, but can be eliminated through long-term action research. Finally, citizens, as end-users of the city's spaces and services demand more focused attention as consumers of the offerings of a smart city. We hope to accord that attention to the citizen's perspectives in our subsequent study.

\section{References}

Albino, V., Berardi, U., and Dangelico, R. M. 2015. "Smart Cities : Definitions, Dimensions , Performance and Initiatives," Journal of Urban Technology (22:1), pp. 3-21. (https://doi.org/10.1080/10630732.2014.942092).

Anthopoulos, L. 2017. "Smart Utopia vs Smart Reality: Learning by Experience from 10 Smart City Cases," Cities (63:March), pp. 128-148. (https://doi.org/10.1016/j.cities.2016.10.005).

Anthopoulos, L., Janssen, M., and Weerakkody, V. 2019. "A Unified Smart City Model (USCM) for Smart City Conceptualization and Benchmarking," in Smart Cities and Smart Spaces: Concepts, Methodologies, Tools, and Applications, USA: IGI Global, pp. 247-264.

Avgerou, C. (forthcoming). "Contextual Explanation: Alternative Approaches and Persistent Challenges," 
MIS Quarterly.

Azad, B., and Faraj, S. 2008. "Making E-Government Systems Workable: Exploring the Evolution of Frames," Journal of Strategic Information Systems (17:2), pp. 75-98. (https://doi.org/10.1016/ j.jsis.2007.12.001).

Bibri, S. E., and Krogstie, J. 2017. "Smart Sustainable Cities of the Future : An Extensive Interdisciplinary Literature Review," Sustainable Cities and Society (31), Elsevier B.V., pp. 183-212. (https://doi.org/10.1016/j.scs.2017.02.016).

Boland, R. J., and Tenkasi, R. V. 1995. "Perspective Making and Perspective Taking in Communities of Knowing,” Organization Science (6:4), pp. 350-372.

Boltanski, L., and Thévenot, L. 2006. On Justification: Economies of Worth, (C. P. (Translated), ed.), Princeton: Princeton University Press.

Boonstra, A., and de Vries, J. 2008. "Managing Stakeholders around Inter-Organizational Systems: A Diagnostic Approach," Journal of Strategic Information Systems (17:3), pp. 190-201. (https://doi.org/10.1016/j.jsis.2008.04.001).

Burte, H. 2014. "The 'Smart City' Card,” Economic \& Political Weekly (XLIX:46), pp. 22-25.

Busch, P. A., Henriksen, H. Z., and Sæbø, Ø. 2018. "Opportunities and Challenges of Digitized Discretionary Practices: A Public Service Worker Perspective," Government Information Quarterly (35:4), Elsevier, pp. 547-556. (https://doi.org/10.1016/j.giq.2018.09.003).

Chibber, V. 2002. "Bureaucratic Rationality and the Developmental State," American Journal of Sociology (107:4), pp. 951-989. (https://doi.org/10.1086/341010).

Chourabi, H., Gil-garcia, J. R., Pardo, T. A., Scholl, H. J., Mellouli, S., Nam, T., Walker, S., and Nahon, K. 2012. "Understanding Smart Cities : An Integrative Framework," in Proceedings of the 45th Hawaii International Conference on System Sciences Understanding, pp. 2289-2297. (https://doi.org/10.1109/HICSS.2012.615).

Cornelissen, J. P., and Werner, M. D. 2014. "Putting Framing in Perspective: A Review of Framing and Frame Analysis across the Management and Organizational Literature," Academy of Management Annals (8:1), pp. 181-235. (https://doi.org/10.1080/19416520.2014.875669).

Cranefield, J., and Pries-heje, J. 2019. "Moving beyond Showcasing: The Five Faces of Leadership in Smart City Transformation," in European Conference on Information Systems, pp. 1-16.

Datta, A. 2015. "New Urban Utopias of Postcolonial India : 'Entrepreneurial Urbanization' in Dholera Smart City, Gujarat," Dialogues in Human Geography (5:1), pp. 3-22. (https://doi.org/10.1177/ 2043820614565748).

Davidson, E. 2002. "Technology Frames and Framing: A Socio-Cognitive Investigation of Requirements Determination," MIS Quarterly (26:4), pp. 329-358.

Davidson, E. 2006. "A Technological Frames Perspective on Information Technology and Organizational Change," Journal of Applied Behavioral Science (42:1), pp. 23-39. (https://doi.org/10.1177/ 0021886305285126).

Davidson, E., and Pai, D. 2004. "Making Sense of Technological Frames: Promise, Progress, and Potential," in Information Systems Research: Relevant Theory and Informed Practice, B. Kaplan, D. P. Truex, D. Wastell, A. T. Wood-Harper, and J. I. DeGross (eds.), Boston, MA: Springer US, pp. 473-491. (https://doi.org/10.1007/1-4020-8095-6_26).

Denis, J. L., Langley, A., and Rouleau, L. 2007. "Strategizing in Pluralistic Contexts: Rethinking Theoretical Frames," Human Relations (6o:1), pp. 179-215. (https://doi.org/10.1177/0018726707075288).

Eden. 2018. "Top 50 Smart City Governments." (https://www.smartcitygovt.com/).

EIU. 2017. "The Urban Transit Evolution.” (https://eiuperspectives.economist.com/sites/default/files/ EIU-Siemens WEB_o.pdf).

Elbanna, A., and Linderoth, H. C. J. 2015. "The Formation of Technology Mental Models: The Case of Voluntary Use of Technology in Organizational Setting," Information Systems Frontiers (17:1), pp. 95-108. (https://doi.org/10.1007/s10796-014-9513-6).

Giffinger, R., Fertner, C., Kramar, H., Kalasek, R., Pichler-Milanović, N., and Meijers, E. 2007. "Smart Cities Ranking of European Medium-Sized Cities.” (http://www.smart-cities.eu/download/ city_ranking_final.pdf).

Giffinger, R., and Gudrun, H. 2010. "Smart Cities Ranking: An Effecttive Instrument for the Positioning of Cities?," ACE: Architecture, City and Environment (4), pp. 7-26.

Gil-Garcia, J. R., Pardo, T. A., and Nam, T. 2015. "What Makes a City Smart? Identifying Core Components and Proposing an Integrative and Comprehensive Conceptualization," Information Polity (20:1), pp. 
61-87. (https://doi.org/10.3233/IP-150354).

GoI. 2016. "Smart Cities Mission." (http://smartcities.gov.in/).

Harris, A. 2015. "Smart Ventures in Modi's Urban India," Dialogues in Human Geography (5:1), pp. 2326. (https://doi.org/10.1177/2043820614565865).

Harrison, C., Eckman, B., Hamilton, R., Hartswick, P., Kalagnanam, J., Paraszczak, J., and Williams, P. 2010. "Foundations for Smarter Cities," IBM Journal of Research \& Development (54:4), pp. 1-16.

Hoelscher, K. 2016. "The Evolution of the Smart Cities Agenda in India," International Area Studies Review (19:1), pp. 28-44. (https://doi.org/10.1177/2233865916632089).

Hoon, J., Gong, M., and Hu, M. 2014. "Towards an Effective Framework for Building Smart Cities : Lessons from Seoul and San Francisco," Technological Forecasting \& Social Change (89), pp. 80-99. (https://doi.org/10.1016/j.techfore.2013.08.033).

IDC. 2019. "IDC's Smart Cities Spending Guide." (https://www.idc.com/getdoc.jsp? containerId=prUS44817419).

Kaplan, S. 2008. "Framing Contests: Strategy Making Under Uncertainty," Organization Science (19:5), pp. 729-752.

Khan, S., Taraporevala, P., and Zerah, Ma.-H. 2018. "Mission Impossible: Defining Indian Smart Cities," Economic and Political Weekly (LIII:49), pp. 80-88. (https://doi.org/10.1097/00005217199613040-00001).

Khosla, R. 2018. "Changing India's Urban and Economic Landscape," Economic and Political Weekly (53:15), pp. 64-72.

Kitchin, R. 2014. "The Real-Time City ? Big Data and Smart Urbanism," GeoJournal (79:November 2013), pp. 1-14. (https://doi.org/10.1007/s10708-013-9516-8).

Kumar, H., Singh, M. K., Gupta, M. P., and Madaan, J. 2018. "Moving towards Smart Cities: Solutions That Lead to the Smart City Transformation Framework," Technological Forecasting and Social Change (30:October 2017), pp. 1-16. (https://doi.org/10.1016/j.techfore.2018.04.024).

Kummitha, R. K. R. 2018. "Entrepreneurial Urbanism and Technological Panacea: Why Smart City Planning Needs to Go Beyond Corporate Visioning?," Technological Forecasting and Social Change (137:September 2017), pp. 330-339. (https://doi.org/10.1016/j.techfore.2018.07.010).

Kummitha, R. K. R., and Crutzen, N. 2019. "Smart Cities and the Citizen-Driven Internet of Things: A Qualitative Inquiry into an Emerging Smart City," Technological Forecasting and Social Change (140:December 2018), pp. 44-53. (https://doi.org/10.1016/j.techfore.2018.12.001).

Madsen, A. K. 2018. "Data in The Smart City: How Incongruent Frames Challenge The Transition from Ideal to Practice," Big Data \& Society (5:2), pp. 1-13.

Mazmanian, M. 2013. "Avoiding the Trap of Constant Connectivity: When Congruent Frames Allow for Heterogeneous Practices," The Academy of Management Journal (56:5), pp. 1225-1250.

Mcloughlin, I., Badham, R., and Couchman, P. 2000. "Rethinking Political Process in Technological Change: Socio-Technical Configurations and Frames," Technology Analysis \& Strategic Management (12:1), pp. 17-37. (https://doi.org/10.1080/095373200107210).

Miles, M. B., and Huberman, M. A. 1994. Qualitative Data Analysis: An Expanded Sourcebook, Thousand Oaks, CA: Sage Publications.

Myers, M. D. 2017. "Coming of Age: Interpretive Research in Information Systems," in The Routledge Companion to Management Information Systems, R. D. Galliers and M.-K. Stein (eds.), Oxon, UK: Routledge, pp. 103-113.

Nam, T., and Pardo, T. A. 2011. "Conceptualizing Smart City with Dimensions of Technology , People , and Institutions," in The Proceedings of the 12th Annual International Conference on Digital Government Research Conceptualizing, pp. 282-291.

Ojo, A., Curry, E., and Janowski, T. 2014. "Designing Next Generation Smart City Initiatives - Harnessing Findings and Lessons From A Study Of Ten Smart City Programs," in Proceedings of the 22nd European Conference on Information Systems, pp. 1-14.

Orlikowski, W. J., and Gash, D. C. 1994. "Technological Frames: Making Sense of Information Technology in Organizations," ACM TransactIons on Information Systems (12:2), pp. 174-207.

Perez-Martinez, P. A., Martinez-Balleste, A., and Solanas, A. 2013. "Privacy in Smart Cities: A Case Study of Smart Public Parking," in Proceedings of the 3rd International Conference on Pervasive Embedded Computing and Communication Systems, pp. 55-59.

Pouloudi, A., and Whitley, E. A. 1997. "Stakeholder Identification in Inter-Organizational Systems: Gaining Insights for Drug Use Management Systems," European Journal of Information Systems (6:1), pp. 1-14. (https://doi.org/10.1057/palgrave.ejis.3000252). 
Praharaj, S., Han, J. H., and Hawken, S. 2018. "Towards the Right Model of Smart City Governance in India," International Journal of Sustainable Development and Planning (13:2), pp. 171-186. (https://doi.org/10.2495/SDP-V13-N2-171-186).

Qamhaieh, A., and Chakravarty, S. 2017. "Global Cities, Public Transportation, and Social Exclusion: A Study of the Bus System in Abu Dhabi," Mobilities (12:3), Routledge, pp. 462-478. (https://doi.org/10.1080/17450101.2016.1139805).

Ramachandran, H. 2014. "Urbanisation: A Solution to Poverty?," Social Change (44:4), pp. 593-603. (https://doi.org/10.1177/0049085714548544).

Rana, N. P., Luthra, S., Mangla, S. K., Islam, R., Roderick, S., and Dwivedi, Y. K. 2018. "Barriers to the Development of Smart Cities in Indian Context," Information Systems Frontiers, pp. 1-23.

Sahu, S. 2018. "Op-Ed: A City Becomes 'Smart' When People Act 'Smart'!," Odisha TV.In. (https://odishatv.in/odisha/op-ed-a-city-becomes-smart-when-people-act-smart-333305).

Tsui-Auch, L. S. 2004. "Bureaucratic Rationality and Nodal Agency in a Developmental State," International Sociology (19:4), pp. 451-477. (https://doi.org/10.1177/0268580904047367).

de Waal, M., and Dignum, M. 2017. "The Citizen in the Smart City . How the Smart City Could Transform Citizenship," It - Information Technology (59:6), pp. 263-273.

Walsham, G. 1995. "Interpretive Case Studies in IS Research: Nature and Method," European Journal of Information Systems (4:2), pp. 74-81.

Webster, C. W. R., and Leleux, C. 2018. "Smart Governance: Opportunities for Technologically-Mediated Citizen Co-Production," Information Polity (23:1), pp. 95-110. (https://doi.org/10.3233/IP-170065).

Wiesman, P. 2011. "We Frame to Please: A Preliminary Examination of the Daily Show's Use of Frames," in The Daily Show and Rhetoric: Arguments, Issues, and Strategies, T. Goodnow and T. G. Knapp (eds.), Lanham MD: Lexington Books.

Young, B., Mathiassen, L., and Davidson, E. 2016. "Inconsistent and Incongruent Frames During ITEnabled Change: An Action Research Study into Sales Process Innovation," Journal of the Association for Information Systems (17:7), pp. 495-520. (https://doi.org/10.17705/1jais.00432).

\section{Appendices}

\section{Appendix 1: A Brief Background of the Smart Cities Mission in India}

Ministry of Housing and Urban Affairs, Government of India introduced the Smart Cities (SC) Mission as a centrally funded initiative in June 2015. MoHUA chose to use a two-stage competition method to select 100 Indian cities for development into SC. The first stage of the competition was intra-state recommendations, followed by a nation-wide city challenge. The shortlisted cities prepared a detailed proposal laying out their plan for retrofitting, redevelopment in 500-acres of the city where an Area-Based Development (ABD) will be implemented. In addition to ABD, pan-city technology-driven smart solutions were proposed to make the city's infrastructure and services more citizen-friendly and efficient. Cities could seek help from professional consultants and external agencies. Cities were also expected to ensure participation from various urban planning and administrative departments and most importantly, the city's residents. The proposals were evaluated by a panel of experts constituted by MoHUA. Over 5 rounds, a total of 99 cities were announced. Each city was then required to form a Special Purpose Vehicle (SPV), legally a limited liability company where the urban local bodies (such as the municipal corporation) and the state government held shares, in order to implement the smart city projects.

\section{Appendix 2: Bhubaneswar - A Brief City Profile}

Bhubaneswar is a 135 sq. $\mathrm{kms}$. (roughly $1 / 4^{\text {th }}$ the size of Mumbai, $1 / 6^{\text {th }}$ the size of New York and $1 / 12^{\text {th }}$ the size of London) has a population of around 1 million. Although the city began its planning as early as 1950s, it has hardly been able to catch up with the increasing needs of its rapidly growing population. As a once historically and culturally vibrant city, Bhubaneswar was often seen as attempting to bridge the socioreligious conflict between the old and the new towns, while presenting the possibility of rapid urbanization to a state otherwise dominated by rural spaces (Kalia 2006). The image of the city, in its past avatar, was that of a "sleepy" unhurried state capital with a much-to-be-desired public transport, bare minimum community spaces, hardly inclusive yet deeply rooted in a sense of tradition. However, the last two decades have seen the city move to becoming an educational hub while also attracting investments from the Indian IT-industry thus influencing the city's social and cultural fabric (Das 2016). 